Original Research Paper

\title{
Analysis of the Factors used by Farmers to Manage Risk. A Case Study on Italian Farms
}

\author{
${ }^{1}$ Antonella Pontrandolfi, ${ }^{2}$ Fabian Capitanio, ${ }^{3}$ Felice Adinolfi and ${ }^{4}$ Barry Goodwin \\ ${ }^{I}$ National Institute of Agricultural Economics, INEA, Rome Italy \\ ${ }^{2}$ Department of Agricultural, University of Naples, "Federico II", Italy \\ ${ }^{3}$ Department of Veterinary Medical Science, University of Bologna, Italy \\ ${ }^{4}$ Department of Agricultural and Resource Economics, NC State University, USA
}

Article history

Received: 01-10-2015

Revised: 17-03-2016

Accepted: 19-03-2016

Corresponding Author:

Fabian Capitanio

Department of Agricultural,

University of Naples, "Federico II", Italy

Email: fabian.capitanio@unina.it

\section{Introduction}

\section{Context}

The present study is the result of research conducted by INEA "Research and technical support on natural disasters, climatic and phytosanitary risks in agriculture and related policies", funded by the Italian Ministry of Agricultural Food and Forestry Policies. The Institute has been studying climate trends and implications in agriculture from more than 10 years. A specific activity

\begin{abstract}
The study analyses the strategies Italian farmers use to cope with the risks that face their production. We develop cross-sectional and longitudinal analyses as well as analyses of correlation that underline the main differences between the way farms adapt their structure and management towards risk. The expected output is an analysis of farms' approach to risk management in relation to the risk exposure. The present study is the result of research conducted by INEA "Research and technical support on natural disasters, climatic and phytosanitary risks in agriculture and related policies", funded by the Italian Ministry of Agricultural Food and Forestry Policies. The main aim of this analysis is to explore the potential and the limitations of economic tools for climatic risk management in agriculture of new CAP 2013-2020 in relation to farms' needs, possible or necessary policies and future directions in the context of the Italian experience (National Solidarity Fund for natural disasters in agriculture, legislative decree n. 102/2004). The chosen approach for the analysis of demand considers the climatic risk at the level of farms' approach to hedging risks in terms of the use of technical tools (agricultural practices, pesticides, fertilizers, irrigation) and economic/financial instruments (insurances, etc.). The results show a preference of technical tools and a strong need of a more integrated policy scheme, arising also from a new system and the potential synergies between risk management tools and other rural development measures of a more structural and management nature. The latter can contribute to a reduction of risk exposure and of the farms' vulnerability, first and foremost through agro-climatic-environmental measures, production diversification, irrigation infrastructures, technological and management innovations and formation-information-consultancy.
\end{abstract}

Keywords: Climatic Risk Management, Policy Assessment, CAP Sustainability, Agriculture and Climate Change, Insurance Schemes has been active since 3 years ago on developing economic tools for climatic risk management, in particular within the National solidarity fund for natural disasters in agriculture that helps farmers through economic aids for insurance premiums and compensation funds. The research activity has been implemented with new scenarios and demands of CAP 2013-2020 that introduced in the II pillar (rural development) some risk management tools (Pontrandolfi, 2013; JEU, 2013). 
With these purposes in mind, the study presented in this report aims to make a scientific contribution to the debate by analysing the demand for risk management tools in agriculture in Italy.

Agriculture in the Mediterranean Basin has a higher degree of exposure and vulnerability to climatic risk as compared to other areas for the following reasons:

- It is based on the quality of production rather than on quantity, so that, equal damages in quantitative terms, correspond to higher economic loss

- Environmental and climatic conditions of Mediterranean countries, especially in Italy, are extremely heterogeneous (Goodwin et al., 2004; Mechle et al., 2013)

In this context, risk management on farms has always represented a crucial factor for the farms' survival.

Concerning in particular the economic risk management tools, they are considered useful, compared, for instance, with structural or infrastructural investments, for their flexibility and adaptability at the stage of definition as well as application (contracts with subject and objectives that can be modified in time and space). "In the context of climate change, such characteristics are even more important (and indeed useful) given the uncertainty associated with the effects and impacts on production. This is because economic tools are adaptable in terms of objectives and substance as different scenarios may unfold (Cafiero et al., 2007; Capitanio et al., 2011; 2014; Goodwin and Mishra, 2006; Diaz-Caneja et al., 2009).

The analysis of such issues in the international context demonstrates that the diffusion of risk management in agriculture through these economic tools, primarily insurances, is based on the possibility of benefiting from supportive public policies" (Pontrandolfi and Nizza, 2011).

The topic of risk management in agriculture has been at the margins of the European debate until last decade. The main reasons lie primarily in the structure of $\mathrm{EEC/EC/EU} \mathrm{intervention,} \mathrm{which,} \mathrm{for} \mathrm{nearly} \mathrm{half} \mathrm{a}$ century, has effectively ensured the presence of mechanisms to stabilize the markets; second, the subsequent development of hedging instruments within individual Member States (MS), particularly those covering production risks, have created prospects for intervention that have not evolved according to common paths. Many of these instruments have developed along very different trajectories, This diversity of instruments available, the ongoing process of EU enlargement and the specific features of the various kinds of agricultural production have led to a complex and heterogeneous set of risk management systems in different Member States which differ in the instrumentation available and the degree of coverage that these practices achieve.

With the phasing out of guarantees provided by the CAP to European farmers in terms of stabilizing markets, the issue of risk management tools is gradually acquiring an ever more important role (EC, 2005; De Castro et al., 2011; Adinolfi et al., 2012). This is reflected in a series of innovations that first appeared in the 2009 'Health Check' and then in the Commission regulation for rural development policy 2014-2020 (reg. 1305/13). It is now possible to use part of the EU funds in order to promote farmers' access to risk management tools.

This innovation therefore concerns only the allocation of resources and not the definition of the specific instruments to be applied in the MS concerned. The forecast in question seeks to promote the management of production risks through incentives for insurance policies and participation in mutual funds to cover direct losses from specific events impacting negatively on the quantity and quality of farm production, such as poor weather, crop and animal diseases, environmental accidents and so forth.

The European Commission's new regulation on rural development policy 2013-2020 (reg. (CE) 1305/13) introduces a collection of measures for risk management in agriculture, providing support for:

- Crop, animal and plant insurance premium subsidies for plans that cover financial losses caused by extreme climatic events or by animal/plant diseases or parasitic infections

- Mutual funds to pay financial compensation to farmers for losses

- An income stabilization tool, in the form of financial contributions to mutual funds to compensate farmers that have suffered a loss of over $30 \%$ of their income

Referring to the Italian experience, several issues need to be deepened and expanded in order to define the future CAP and to evolve the risk management system. In particular the most critical and common points are:

- The lack of preliminary analysis on risk conditions (parameters, risk levels and interrelations) and risk assessment that explain and justify the choices made on policies and public aid

- The lack of analysis on demand for risk management tools, with policies oriented more to the market supply (insurances); this tendency can create an inefficiency and ineffectiveness of policy and the tools (economic aids even for notinsurable risks, consequent unbalance between contributions to premiums and ability of 
companies to indemnify damages, insufficient financial coverage of damages)

- A low level of integration among the available risk management strategies (a reduction of exposure and vulnerability, transferring and acceptance) and a policy focus confined to the transfer of risk

- Risk management through economic tools should represent just one component of a wider strategy. Only a multilevel approach (at farm and territorial levels, with management and structural measures)will ensure the effectiveness of policies in the long term

In light of these considerations, it is important to evaluate the contributions that economic tools for risk management can bring in the new context of CAP, in relation to farms' needs and approaches. Moreover, it is crucial that, when designing these tools, consistency with other key agricultural objectives is ensured with other CAP subsidies (Chatellier, 2011).

The chosen approach for the analysis of demand considers the farms' approach to hedging risks in terms of the use of technical tools (agricultural practices, pesticides, fertilizers, irrigation) and economic/financial instruments (insurances, etc.). The research analyses the strategies Italian farmers use to cope with the risks that they face in production through cross-sectional and longitudinal analyses as well as analyses of correlation that underline the main differences between the way farms adapt their structure and management towards risk (Capitanio and Adinolfi, 2009; Di Falco et al., 2014).

\section{Methodology and Dataset}

The database is taken from the Italian Farm Accountancy Data Network (FADN) (The Farm Accountancy Data Network (FADN) has been created to satisfy the information needs of the European Union relating to the business operation of agricultural enterprises. INEA manages the database for Italy (www.inea.it)) for farm characteristics at the provincial/regional level. Data on insured farms are also available.

The indicators describing the choices to manage risk at the farm level include different tools for risk management, technical and financial instruments. In particular, the indicators chosen for the analysis are.

\section{Technical Tools}

- Diversification (numbers of different crops, mix crop-animals, etc.)

- Use of chemical inputs (pesticides and nutrients)

- Irrigation (presence and systems)

- Advice service (presence and type of service)
- Farm certification

- Costs for maintenance

- Investments in new techniques and machines

\section{Financial Tools}

- Savings

- Insurance

- Type of trade (wholesale, retail, consumers, cooperative regular VAT, cooperative special VAT, industry)

- Cash level of the farm

- EU payments

The dataset used for the analysis is the Italian farm accountancy data network (FADN-RICA), which provides very precise information at the individual scale (the main mission of FADN is farm accountancy). This national sample is stratified according to the region, the economic dimension and the specialization of the farm (Enjolras et al., 2012; 2014). It provides outstanding information regarding the annual accounting of Italian farms. A precise study of the operating expenses allows to identify and to measure with precision the roles of different risk management tools that are used by farmers to cope with risk, either technical or financial, e.g., crop diversification and crop insurance.

Given the need for a longitudinal analysis, the sample is made up of 3,213 professional Italian farms that are continuously surveyed between 2005 and 2012. This balanced sample allows for comparisons among years and for a study of the dynamics of Italian farms regarding risk management.

Within the FADN database, the choice of the variables takes into account:

- The structure of the farm, considering its total, cultivated and irrigated area

- The equipment of the farm through the mechanization, investments and amortizations

- The activity of the farm, given total and sold production, as well cost structure

- The financial structure of the farm including fixed and operating capital as well as land owned

- Risk management tools such as crop insurance, consultancy and CAP payments

- Crop production, considering both its characteristics (cultivated area, income, number of crops and cost structure) and operating expenses (seeds, water, chemical inputs, crop insurance, consultancy and certification)

- Livestock (area, income and expenses, number of product, insurance and certification)

- Transformed products (income and number of products) 


\section{Specific Categories}

The analysis is carried out at the national level. However, for the sake of precision, the analysis may be broken down according to the main regions, farm production and economic dimension. The detail of these categories is provided below (Table 1). The regions are grouped according three main areas:

- North: Valle D’Aosta, Piemonte, Lombardia, Trentino, Alto Adige, Veneto, Friuli Venezia, Giulia, Liguria and Emilia Romagna

- Centre: Toscana, Marche, Umbria and Lazio

- South and Islands: Abruzzo, Molise, Campania, Calabria, Puglia, Basilicata, Sicilia and Sardegna

Farm production is also grouped according to these main categories:

- Specialization in field crops

- Specialization in fruits and vegetables

- Specialization in meat

- Mix

The economic dimension is also taken into account through the European Dimension Units (EDU) ranked in 7 classes. UDE 1 and 2 are not relevant due to the very low number of observations. UDE 4,5 and 6 are the most numerous (Table 2).

\section{Analysis of Data}

From a very general point of view, the structure of Italian farms of the sample has not changed much between 2005 and 2012 (Fig. 1). Over that period, the total area has only increased by $3.5 \%$ while the total Usable Agricultural Area (UAA) rose at the same time from the same proportion. The irrigated UAA remains quite stable and represents on average $30 \%$ of the UAA in 2012. This result seems to indicate that the CAP did not affect the fundamental structure of Italian farms over the last years.

By contrast, the financial analysis of the same farms reveals notable changes (Fig. 2). The total and marketed production increased respectively by 14 and $16 \%$. The most important change comes from the costs structure, which evolved towards a more flexible model. Fixed costs dropped by $37 \%$ while variable costs increased by $30 \%$ over the period. One should notice that variable costs include risk management practices such as buying crop insurance policies or chemical inputs. As a result, Italian farms reduce their break-even point, thus becoming less sensitive to changes in their income level while protecting it at the same time. Yet, amortizations are generally greater than investments regarding machinery, which may lead to a progressive obsolescence of production factors.
Table 1. Repartition of Italian farms of the sample in 2012 according to their region and specialization

\begin{tabular}{lrccrr}
\hline Region & $\begin{array}{l}\text { Field } \\
\text { crops }\end{array}$ & $\begin{array}{l}\text { Fruits/ } \\
\text { vegetables }\end{array}$ & Meat & Mix & \multicolumn{1}{c}{ Total } \\
\hline North & 409 & 645 & 372 & 41 & 1,467 \\
Centre & 235 & 165 & 106 & 33 & 539 \\
South/Islands & 381 & 506 & 254 & 66 & 1,207 \\
Total & 1,025 & 1,316 & 732 & 140 & 3,213 \\
\hline
\end{tabular}

Source: Elaboration INEA on FADN data

Table 2. Repartition of Italian farms of the sample in 2012 according to their UDE and specialization

\begin{tabular}{|c|c|c|c|c|c|}
\hline UDE & $\begin{array}{l}\text { Field } \\
\text { crops }\end{array}$ & $\begin{array}{l}\text { Fruits/ } \\
\text { vegetables }\end{array}$ & Meat & Mix & Total \\
\hline 1 & 0 & 0 & 0 & 0 & 0 \\
\hline 2 & 67 & 57 & 2 & 2 & 128 \\
\hline 3 & 335 & 307 & 74 & 43 & 759 \\
\hline 4 & 207 & 334 & 134 & 37 & 712 \\
\hline 5 & 188 & 291 & 163 & 32 & 674 \\
\hline 6 & 205 & 302 & 272 & 21 & 800 \\
\hline 7 & 17 & 18 & 40 & 2 & 77 \\
\hline 8 & 6 & 7 & 47 & 3 & 63 \\
\hline Total & 1,025 & 1,316 & 732 & 140 & 3,213 \\
\hline
\end{tabular}

Source: Elaboration INEA on FADN data

Charges devoted to risk management are classified among variable costs due to their optional and activitydependent characteristics (Fig. 3). Observing in detail the structure of variable costs shows that expenses in risk management tools have notably increased. For instance, the costs of fertilizers and pesticides, which are commonly used to protect crop yields, respectively increased annually by 6 and 4\%. Crop insurance premiums have increased by 2.2 times while the number of farms subscribing crop insurance policies rose by 1.5 times since 2005 , when the reform of the national crop insurance system was implemented. Moreover, between 2008 and 2012, consultancy costs increased by $35 \%$.

Water is a particular kind of input: While it is essential for crop production, it is subject to pressures on its availability due to drought episodes and its use and related cost is fixed by specific policies, because of the public nature of water resources, so the cost is not subject to market dynamics. Over the period of study, the cost of water remained quite low compared to other inputs. It increased annually by $6 \%$ but this trend hides wide disparities among years, with the highest expenses being made in 2009 and not within the driest years.

The results clearly exhibit two trends that are amplified overtime: (1) Italian farms get significantly more coverage against natural hazards in the crop sector, whatever the intrument considered; (2) technical tools are prefered to financial tools, mainly for their flexibility and a limited cost per unit. For instance, an application of chemical inputs on crops can be done on request, while crop insurance subscripton needs to be done before 
the season begins. Given the relative stability of the structure of the farms included in the sample, we can infer that farmers combine rather than they substitute risk management tools.

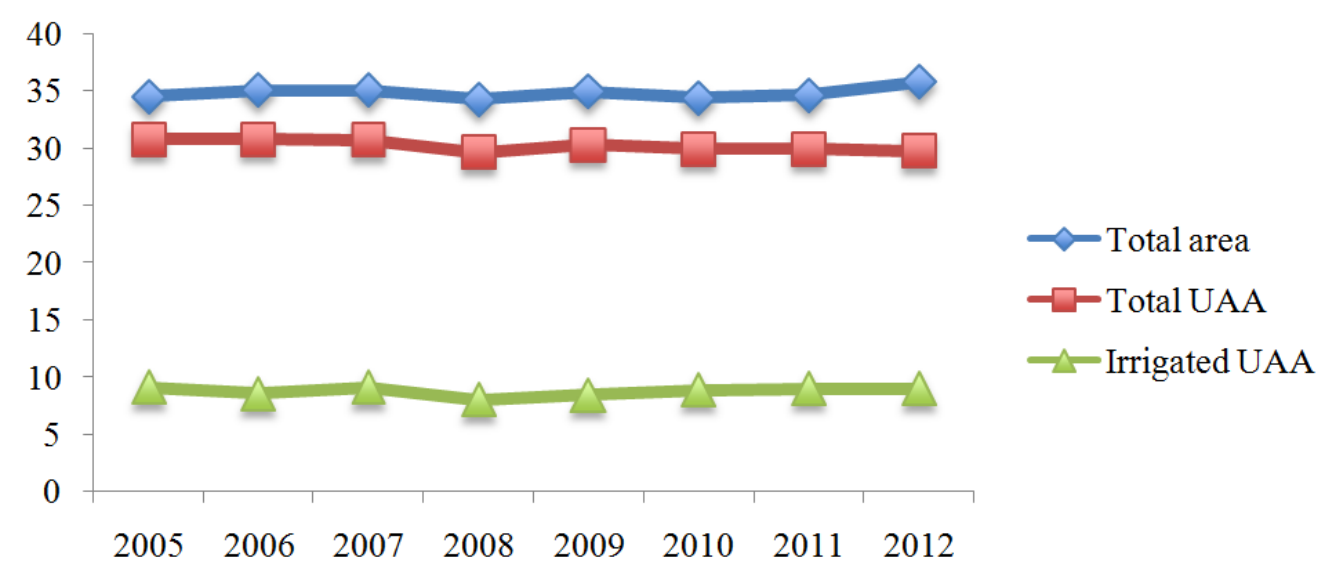

Fig. 1. Structure of Italian farms between 2005 and 2012 according to the sample (all farms, mean values in ha) Source: Elaboration INEA on FADN data

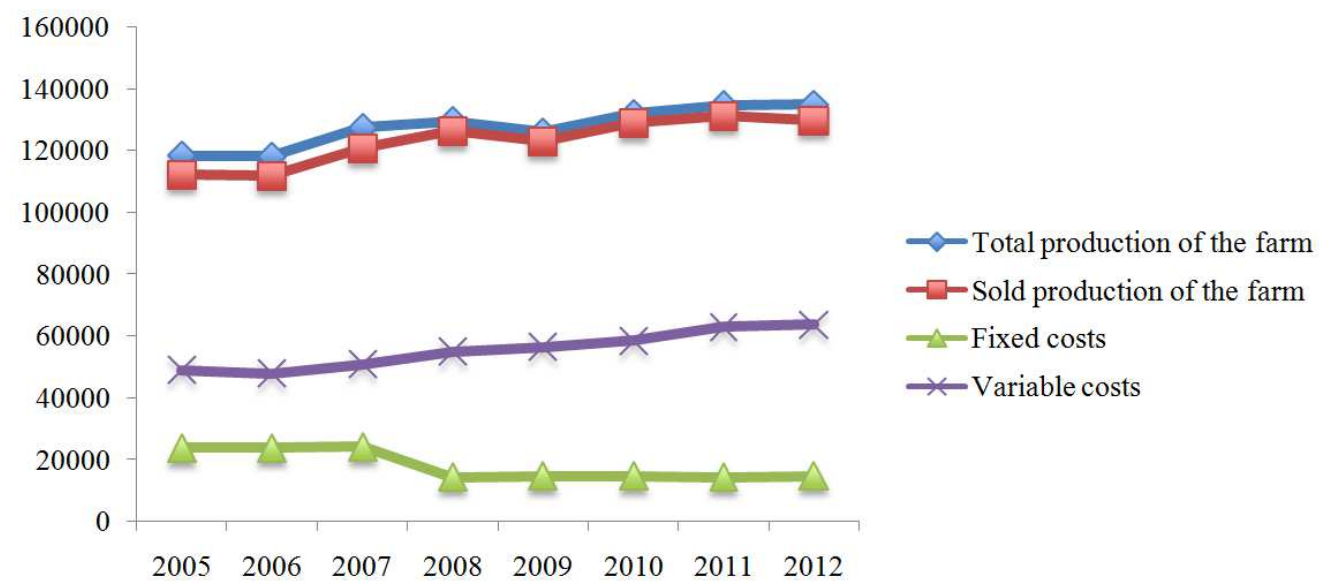

Fig. 2. Financial analysis of Italian farms between 2005 and 2012 according to the sample (all farms, mean values in $€$ ) Source: Elaboration INEA on FADN data

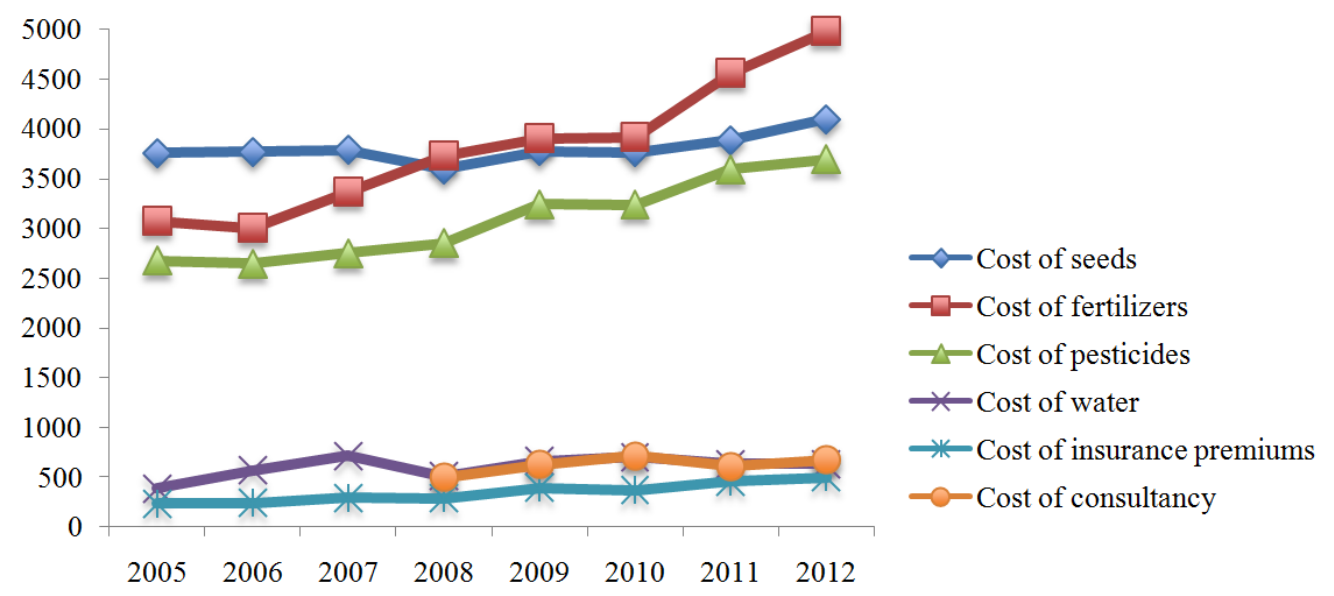

Fig. 3. Evolution of expenses for crop production between 2005 and 2012 according to the sample (all farms, mean values in $€$ ) Source: Elaboration INEA on FADN data 


\section{Geographic Distribution}

There exist strong regional disparities among Italian farms. Farms located in the Centre of the country are much larger (40 ha in 2012) than those located in the North and the South (respectively 27 ha and 29 ha in 2012). However, total production in the North and the Centre are somehow comparable while the South has very low levels of production. Moreover, farms located in the north of Italy use the most fertilizers, pesticides and crop insurance. Despite these structural differences which denote a higher productivity when moving northward, we notice the same trends overtime that at the national scale, i.e., the stability of UAA and increases in total production. Indeed, the evolution of the cost structure is similar with a decrease in fixed costs and an increase in variable costs. In line with that result, one can also notice that the main expenses made for managing crop risk are dramatically increasing in all areas (Fig. 4).

The dynamics in the use of risk management tools differs among the location: The use of fertilizers increase the most in the North, the use of pesticides increase the most in the Centre and the use of crop insurance policies increase the most in the Centre. Despite huge annual variations, the cost of water remains broadly stable on average between 2005 and 2012 , except in the Centre where it increases by $75 \%$ over the period.

\section{Differentiation in Production}

We differentiate four main types of farm production (field crops, fruits and vegetables, meat and mix). Studying the mix of production, which combines both crops and animals, leads to results difficult to analyse. The reason is the small number of farms classified in this category. Then, we compare the evolution of expenses devoted to crop or cattle insurance and to consultancy. These two instruments, whose use is strongly encouraged within the CAP for risk management, are available for all types of production. While insurance is used to hedge yield risk, consultancy aims at helping the farmer to adopt optimal practices.

The structures of farms that cultivate field crops and those that grow fruits and vegetables are clearly different (Fig. 5). The former are associated with a greater UAA and owned land as well as greater resulting production. As a result, farms cultivating field crops are the most insured. One must also note that crop insurance policies were primarily designed for this category of farms, which explains the strong and continuous increase of crop insurance subscription since 2003. The recent development of crop insurance policies devoted to fruits and vegetables offers these sectors a new opportunity to hedge their risks. Consultancy costs follow generally a positive and similar trend regardless of the crop considered. It also appears that farmers devote annually the same amount of funds to crop insurance and consultancy. Moreover, the use of these two instruments does not appear to be correlated, probably because they do not cover the same kinds of risks.

Meat production can also be insured and benefit from consultancy. However, the costs of both instruments remain very low. Since at least 2008 breeders have spent more money in consultancy than in livestock insurance. Such behaviour may be explained by the relative inefficiency of current insurance tools in relation to the needs of farmers.

\section{Size Matters}

We study in this subsection the influence of farm size (measured by its economic dimension) on risk management strategies. The results offer a contrasted view of crop insurance practices (Fig. 6). Except for the minority of farms belonging to UDE2 and UDE8, expenses in crop insurance are strongly increasing over the period $2005-2012$ (e.g., $+764 \%$, i.e., $+31 \%$ annually, for UDE4 which includes a large number of Italian farms).

However, such an increase is mainly due to a very low starting point (the legislative reform of 2004 started in 2005). In fact, only the biggest farms (UDE7 and UDE8) fully benefit from crop insurance with expenses rising annually by $18 \%$ and $13 \%$, respectively. Similar observations can be made regarding the costs of consultancy as well as chemical inputs: Medium farms are the most dynamic regarding risk management but only rich farms can afford the cost of the coverage.

\section{Combination of Risk Management Strategies}

Descriptive statistics can be complemented by an analysis of the relationships between risk management strategies because farmers have the choice to use simultaneously many instruments. A convenient way to study dependencies among costs devoted to risk hedging (indicators described before), is to compute coefficients of correlations. The indicators determine the degree to which two variables movements are associated, with a range comprised between -1 (perfect negative correlation, i.e., perfect substitution of instruments) and 1 (perfect positive correlation, i.e., perfect complementary of instruments), 0 meaning no correlation at all. The significance of the Correlation Coefficient (CC) is measured at the 5\% level (denoted with a star in the tables), which is the standard confidence interval in statistics. Throughout the analysis, the large number of observations in the sample guarantees significance for most associations, even with very low correlation coefficients. 


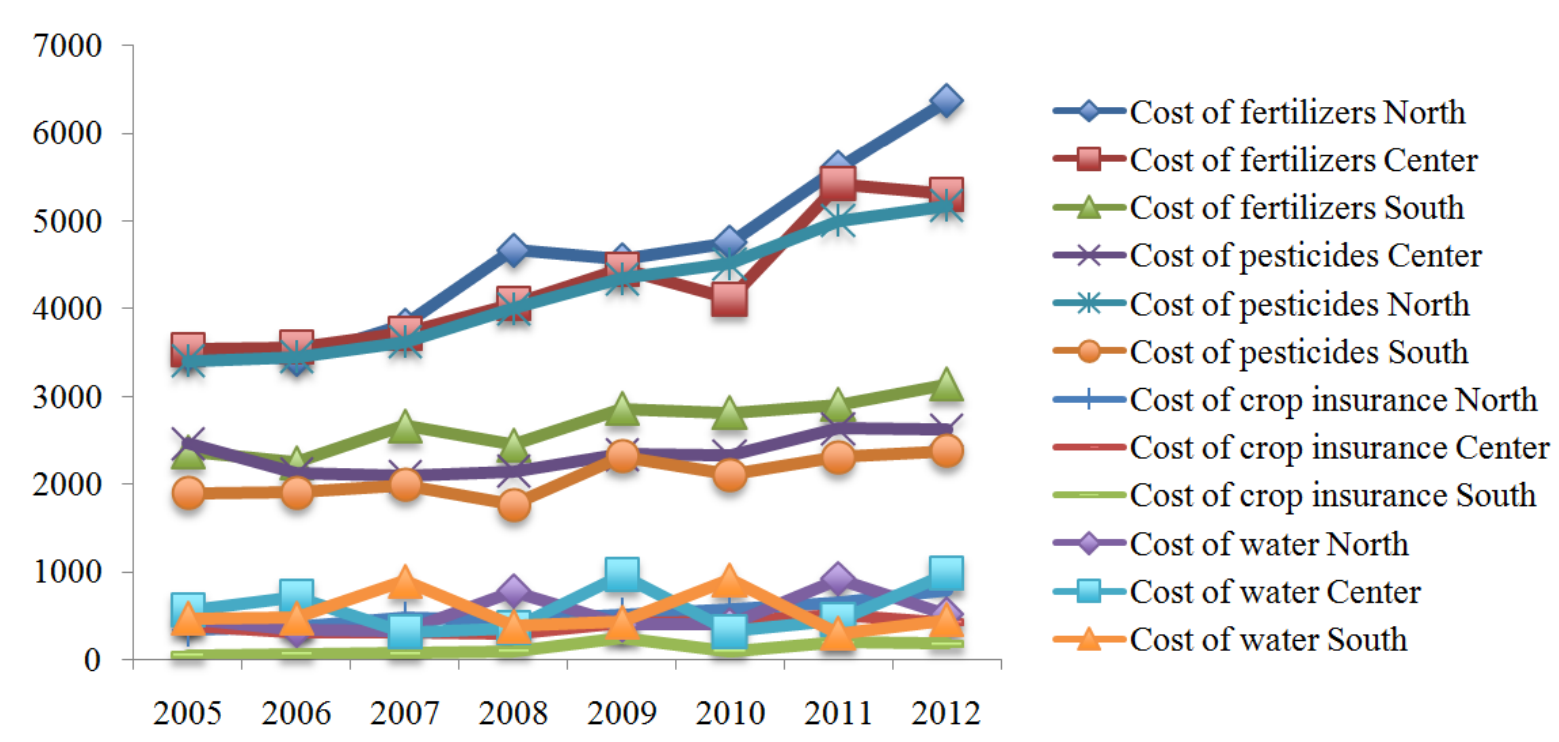

Fig. 4. Evolution of expenses for crop production for Italian farms of the sample between 2005 and 2012 according to their location (all farms, mean values in $€$ ) Source: Elaboration INEA on FADN data

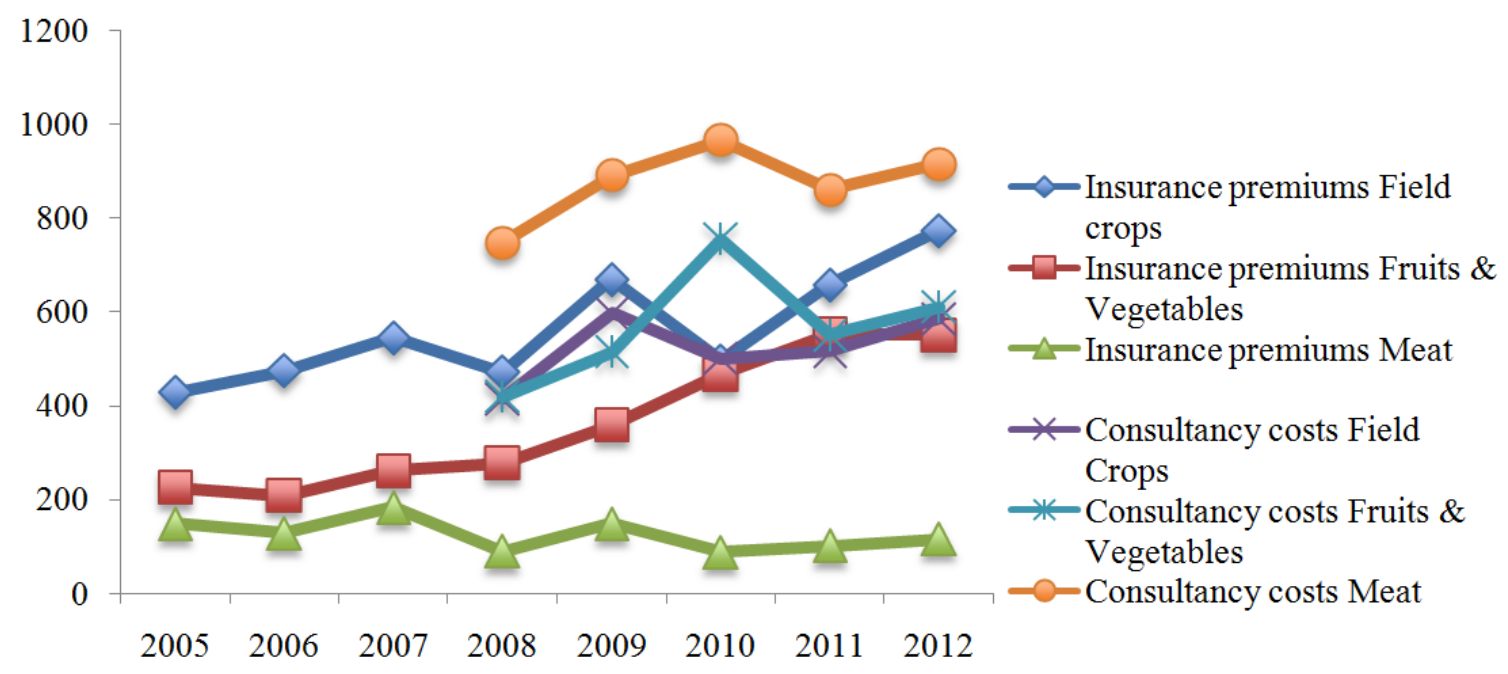

Fig. 5. Evolution of insurance and consultancy costs for Italian farms of the sample between 2005 and 2012 according to their production type (all farms, mean values in $€$ ) Source: Elaboration INEA on FADN data

\section{Animals}

Regarding animal breeding, the number of products is almost independent of the sold production $(\mathrm{CC}=$ 0.1789 , close to 0 ) but rather is linked to the farmed area $(\mathrm{CC}=0.8427$, close to 1$)$. The same relationship is observed between the level of insurance premiums and the area (Table 3). One should notice that crop insurance and certification are quite independent because these strategies correspond to different aims, i.e., protection versus valorisation of the production.

\section{Crops}

We notice that the costs of seeds, fertilizers and pesticides are largely linked to the sold production
(Table 4). Therefore, farms make such expenditures according to the level of income they are expecting. Conversely, the relation between the sold production and the number of crops is very weak, which appears to be a choice linked to the cultivated area.

Crop insurance, consultancy and certification appear to be used independently of both the production structure (cultivated area, number of crops) and the context of risk management (chemical inputs). They are employed in specific contexts and not systematically. For instance, $18 \%$ of all Italian farms sell at least one certified product. This proportion varies among sectors but it systematically remains stable overtime. 


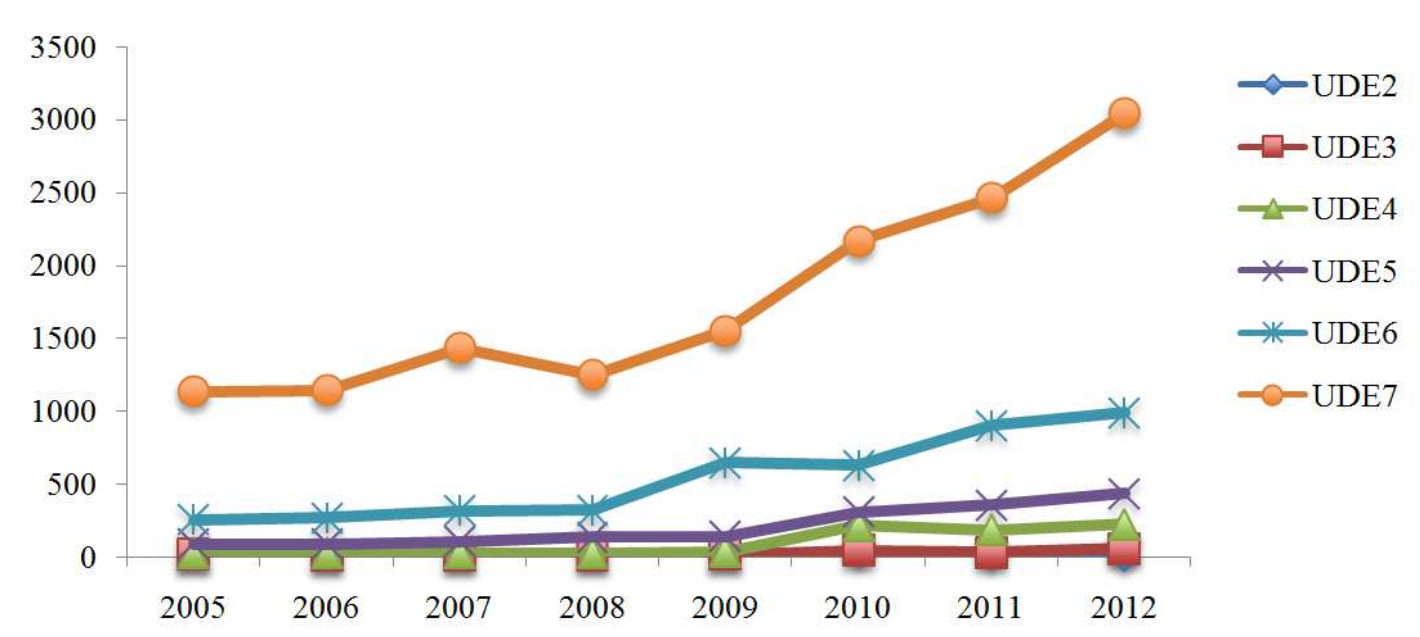

Fig. 6. Evolution of crop insurance premiums for Italian farms of the sample between 2005 and 2012 according to their economic dimension (all farms, mean values in $€$ ) Source: Elaboration INEA on FADN data

Table 3. Matrix of correlation between livestock revenue and risk management tools according to the sample (all farms, all years)

\begin{tabular}{|c|c|c|c|c|c|c|}
\hline $\begin{array}{l}\text { Correlation } \\
\text { Coefficient (CC) }\end{array}$ & $\begin{array}{l}\text { Sold } \\
\text { production }\end{array}$ & $\begin{array}{l}\text { Operating } \\
\text { expenses }\end{array}$ & $\begin{array}{l}\text { Number of } \\
\text { products }\end{array}$ & $\begin{array}{l}\text { Area } \\
\text { (UBA) }\end{array}$ & $\begin{array}{l}\text { Insurance } \\
\text { premiums }\end{array}$ & $\begin{array}{l}\text { Being } \\
\text { certified }\end{array}$ \\
\hline Sold production & 1.0000 & & & & & \\
\hline Operating expenses & $0.8966^{*}$ & 1.0000 & & & & \\
\hline Number of products & $0.1789 *$ & $0.1340 *$ & 1.0000 & & & \\
\hline Area (UBA) & $0.8427 *$ & $0.8509 *$ & $0.2166^{*}$ & 1.0000 & & \\
\hline Insurance premiums & $0.2702 *$ & $0.3443^{*}$ & $0.1094 *$ & $0.2778^{*}$ & 1.0000 & \\
\hline Being certified & $0.0423 *$ & $0.0241 *$ & $0.1787^{*}$ & $0.0410 *$ & $0.0241 *$ & 1.0000 \\
\hline
\end{tabular}

Note: * indicates a correlation significant at the $5 \%$ level

Source: Elaboration INEA on FADN data

$\underline{\text { Table 4. Matrix of correlation between crop revenue and risk management tools according to the sample (all farms, all years) }}$

\begin{tabular}{|c|c|c|c|c|c|c|c|c|c|c|c|c|c|c|}
\hline $\begin{array}{l}\text { Number of } \\
\text { Correlation } \\
\text { Coefficient (CC) }\end{array}$ & $\begin{array}{l}\text { Sold } \\
\text { operating }\end{array}$ & $\begin{array}{l}\text { Operating } \\
\text { expenses }\end{array}$ & $\begin{array}{l}\text { Variable } \\
\text { different } \\
\text { crops }\end{array}$ & $\begin{array}{l}\text { Cost } \\
\text { Area } \\
\text { (UBA) }\end{array}$ & $\begin{array}{l}\text { Variable } \\
\text { costs }\end{array}$ & $\begin{array}{l}\text { cost } \\
\text { margin }\end{array}$ & $\begin{array}{l}\text { of } \\
\text { seeds }\end{array}$ & $\begin{array}{l}\text { Cost of } \\
\text { fertilizer }\end{array}$ & $\begin{array}{l}\text { Cost of } \\
\text { spesticides }\end{array}$ & $\begin{array}{l}\text { Cost } \\
\text { of } \\
\text { water }\end{array}$ & $\begin{array}{l}\text { Crop } \\
\text { insurance } \\
\text { premium }\end{array}$ & $\begin{array}{l}\text { Cost } \\
\text { of cons } \\
\text { ultancy }\end{array}$ & $\begin{array}{l}\text { Being } \\
\text { certified }\end{array}$ & $\begin{array}{l}\text { Miscell } \\
\text { aneous } \\
\text { costs }\end{array}$ \\
\hline Sold Production & 1.0000 & & & & & & & & & & & & & \\
\hline $\begin{array}{l}\text { Operating expenses } \\
\text { Number of } \\
\text { different crops }\end{array}$ & $\begin{array}{l}0.8349^{*} \\
0.0797^{*}\end{array}$ & $\begin{array}{l}1.0000 \\
0.0708^{*}\end{array}$ & 1.000 & & & & & & & & & & & \\
\hline Area(UBA) & $0.3910^{*}$ & $0.3673^{*}$ & $0.2008^{*}$ & 1.0000 & & & & & & & & & & \\
\hline Variable costs & $0.8478^{*}$ & 0.9847 & 0.1063 & $0.4381^{*}$ & 1.0000 & & & & & & & & & \\
\hline Variable cost margin & $1.0000^{*}$ & $0.8465^{*}$ & $0.1002^{*}$ & $0.4251^{*}$ & $0.8478^{*}$ & 1.0000 & & & & & & & & \\
\hline Cost of seeds & $0.6337^{*}$ & $0.7954^{*}$ & $0.0378^{*}$ & $0.1860^{*}$ & $0.7614^{*}$ & $0.6665^{*}$ & 1.0000 & & & & & & & \\
\hline Cost of fertilizers & $0.6797^{*}$ & $0.7420^{*}$ & $0.1254^{*}$ & $0.5763^{*}$ & $0.7593^{*}$ & $0.6978^{*}$ & $0.4349^{*}$ & 1.0000 & & & & & & \\
\hline Cost of pesticides & $0.7029^{*}$ & $0.7102^{*}$ & $0.0868^{*}$ & $0.3991^{*}$ & $0.7216^{*}$ & $0.7222^{*}$ & $0.3785^{*}$ & $0.7042^{*}$ & 1.0000 & & & & & \\
\hline Cost of water & $0.3810^{*}$ & $0.4195^{*}$ & $-0.0248^{*}$ & $0.2168^{*}$ & $0.3846^{*}$ & $0.3607^{*}$ & $0.2756^{*}$ & $0.3670^{*}$ & $0.3864^{*}$ & 1.0000 & & & & \\
\hline Crop insurance premium & $0.2875^{*}$ & $0.3398^{*}$ & $-0.0184^{*}$ & $0.1084^{*}$ & $0.3386^{*}$ & $0.2592^{*}$ & $0.1108^{*}$ & $0.2223^{*}$ & $0.3152^{*}$ & $0.2107^{*}$ & 1.0000 & & & \\
\hline Cost of consultancy & $0.2940^{*}$ & $0.3725^{*}$ & $0.1420^{*}$ & $0.4209^{*}$ & $0.4041^{*}$ & $0.3128^{*}$ & $0.1383^{*}$ & $0.4581^{*}$ & $0.3506^{*}$ & $0.1200^{*}$ & $0.0952^{*}$ & 1.0000 & & \\
\hline Being certified & $0.0128^{*}$ & $-0.0172^{*}$ & $0.0799^{*}$ & $-0.0076^{*}$ & $-0.0206^{*}$ & $-0.0045^{*}$ & $-0.0328^{*}$ & $-0.0245^{*}$ & $0.0362^{*}$ & $-0.0270^{*}$ & $0.0317^{*}$ & $-0.0060^{*}$ & 1.0000 & \\
\hline Miscellaneous costs & $0.5267^{*}$ & $0.6948^{*}$ & -0.0100 & $0.0402^{*}$ & $0.6472^{*}$ & $0.4745^{*}$ & $0.3789^{*}$ & $0.2920^{*}$ & $0.3139^{*}$ & $0.1510^{*}$ & $0.2643^{*}$ & $0.0374^{*}$ & -00092 & 1.0000 \\
\hline
\end{tabular}

Note: * indicates a correlation significant at the $5 \%$ level

Source: Elaboration INEA on FADN data

Both the intensity of the correlations and their significance level are preserved among farm specialization, location and dimension.

\section{Focus on the Influence of Crop Insurance in Farm Management}

In this sub-section, we focus more specifically on crop insurance subscription in order to understand which farms are insured and the consequences in terms of farm income and risk management.

\section{Insured Farmers}

Thanks to a changing institutional context (cfr. parr. 1.1 and 2.1), farmers who decide to subscribe to crop insurance policies are more numerous each year (Fig. 7).

This regular increase concerns all regions and specialities, however we can notice strong disparities according to our sub-classifications (Table 5). For instance, being in the North of Italy doubles the probability of insuring the crops. Not surprisingly, farms 
specialized in field crops or fruits and vegetables are more willing to insure their crops than farms that mix their production because the latter are more diversified. The economic dimension is finally a discriminant indicator because the larger is the farm the more it is insured.

When considering the detail, it appears clear that insured farms benefit from higher sold production which is quite volatile overtime (Fig. 8). The charges induced by crop insurance premiums and the costs associated with other risk management strategies lead to an increase in variable costs after 2010 but this increase is more than compensated by a rise in the sold production. As a result, insured farms benefit from a higher variable cost margin. This indicator, which is computed as the difference between the sold production and the sum of variable costs, is associated with economic performance.

Non-insured farms benefit from a more stable sold production $(+2 \%$ annually), which may justify their choice to avoid insurance. Yet, the level of variable costs increases at a higher rhythm ( $+4 \%$ annually), which leads to a continuous decrease of the variable cost margin since 2010. This result denotes a decreasing competitiveness of non-insured farms (Goodwin et al., 2004).

\section{Being Insured and Risk Management}

Insured farmers benefit from higher CAP payments, because their farms are fundamentally larger (Fig. 9). Yet, these payments are very irregular. After a continuous pace of growth, they continuously decreased after 2006, despite a slight increase in 2009 and 2012. Non-insured farms are in an opposite situation because the CAP payments they receive increased by $10 \%$ between 2005 and 2012. CAP payments therefore seem more and more targeted toward small farms. The result is that European subsidies cover on average $100 \%$ of variable costs for non-insured farms while they only cover between 70 and $100 \%$ of such costs for insured farms.

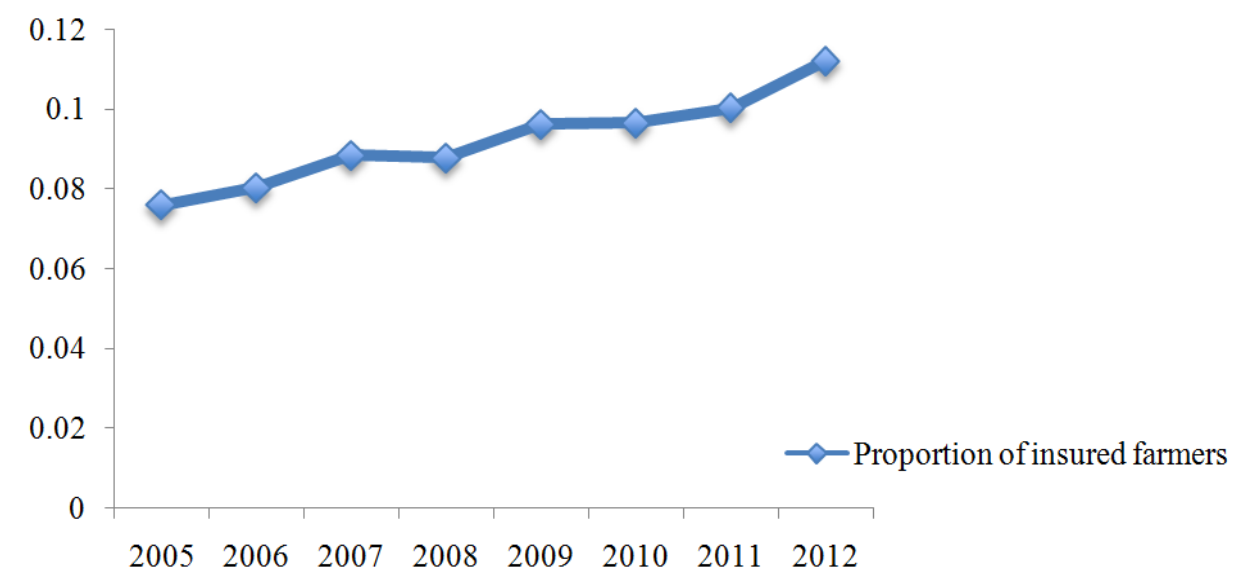

Fig. 7. Proportion of insured farms of the sample between 2005 and 2012 (all farms, in \%) Source: Elaboration INEA on FADN data

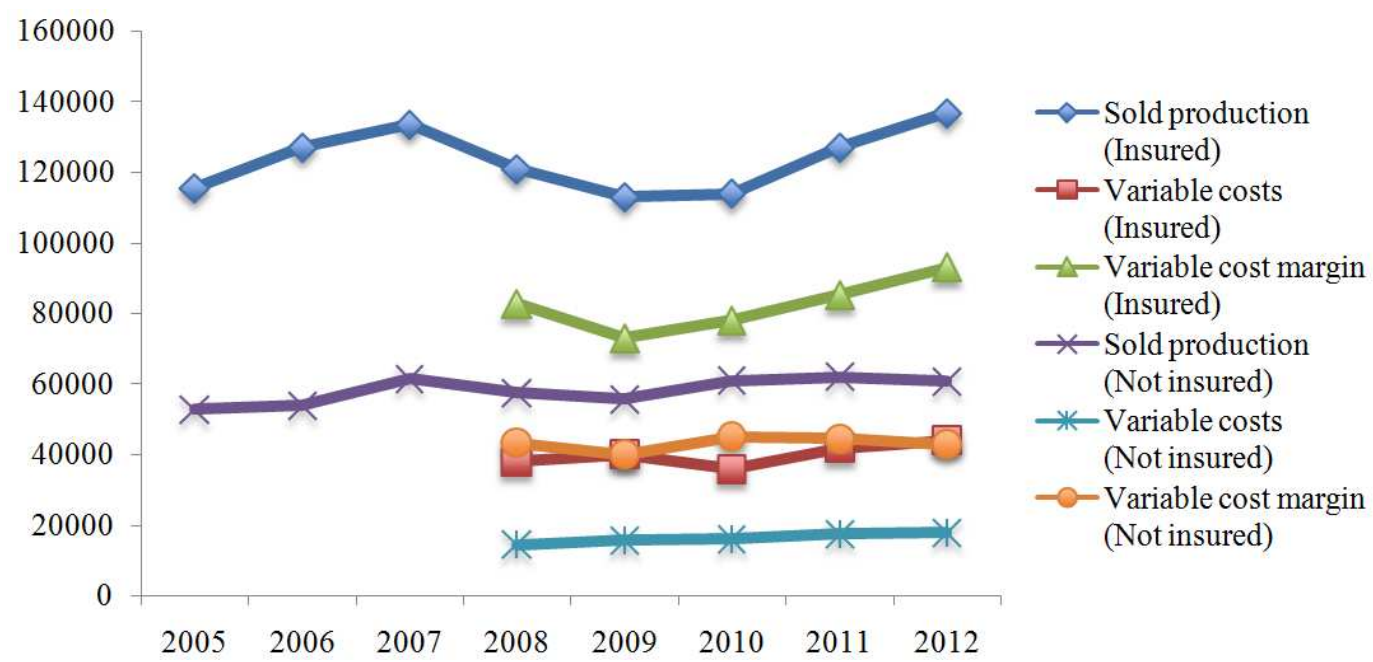

Fig. 8. Financial analysis of insured and non-insured farms of the sample between 2005 and 2012 (all farms, in $€$ ) Source: Elaboration INEA on FADN data 


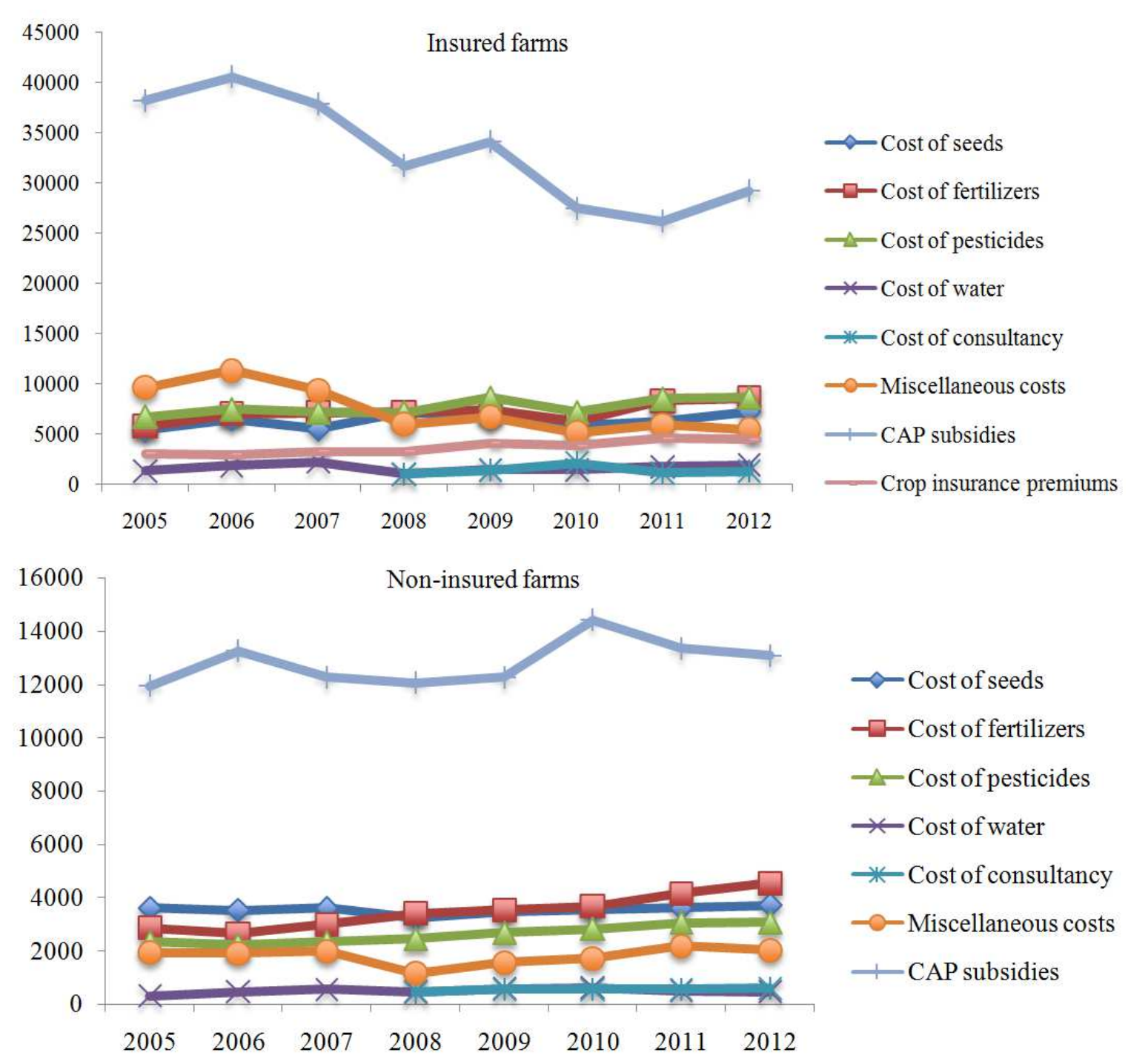

Fig. 9. Evolution of expenses for crop production between 2005 and 2012 for insured and non-insured farms of the sample (all farms, mean values, in $€$ ) Source: Elaboration INEA on FADN data

Table 5. Proportion of insured farmers of the sample according to their location, specialization and economic dimension (all farms, all years, in \%)

\begin{tabular}{llll}
\hline & & Insured & Not insured \\
\hline Region & North & 12,1 & 87,9 \\
& Centre & 9,0 & 91,0 \\
& South & 5,8 & 94,2 \\
Specialization & Field crops & 10,9 & 89,1 \\
& Fruits/vegetables & 12,5 & 87,5 \\
& Meat & 1,6 & 98,4 \\
Economic & Mix & 4,1 & 95,9 \\
dimension & UDE2 & 4,5 & 95,5 \\
& UDE3 & 4,6 & 95,4 \\
& UDE4 & 6,1 & 93,9 \\
& UDE5 & 9,2 & 90,8 \\
& UDE6 & 13,1 & 86,9 \\
& UDE7 & 15,4 & 84,6 \\
& UDE8 & 13,9 & 86,1 \\
\hline
\end{tabular}

Source: Elaboration INEA on FADN data
Given that context, it is not surprising to observe that non-insured farms increase their level of variable charges as CAP subsidies increase. Over the period 2005-2012, all charges increased, especially pesticides and fertilizers. Although very small, consultancy costs increased too. Facing a drop in CAP subsidies, insured farms tried to stabilize their variable costs by reducing drastically miscellaneous costs in favour of identified risk management tools. Between 2008 and 2012, the value of consultancy costs increases by $26 \%$, while insurance premiums rise by $44 \%$. A dichotomy between insured and non-insured farms can be observed regarding expenses in seeds: Being insured, a farmer is incentivized to select more expensive plants. 


\section{Conclusion}

Taking into account the methodological approach and the dataset, it is possible to find significant elements that should give cause for thought for the design of the risk management tools in the new CAP.

The following key points suggested by the analysis show that in perspective it may be more effective to rethink the policy design rather than adjust it each time it is necessary, that is each year.

Italian farms benefit from a wide range of instruments able to help them to face risks. While their use is globally growing, such trends must be discussed and placed in the context of contrasted regions, productions and economics dimensions.

The behaviour of farms seems not to have really changed in order to adapt to climatic risks. The structure of farms does not seem to be affected by the CAP during the period 2003-2012.

In fact, only large and rich farms can afford all additional expenses required to hedge risk (crop insurance, pesticides, fertilizers, water and consultancy). They do so without changing their production structure overtime.

In case of a drop in the sold production, those farms having a higher proportion of variable costs are able to reduce their variables charges, thus getting more flexibility.

Among the instruments used to hedge risks, the technical ones, use of chemical inputs and water, are the most employed.

Insurance is marginally used, both to cover crop and animal yields, despite a trend favourable to its development.

The population of crop-insured farmers exhibits a different behaviour compared to non-insured producers that is characterized by the development of alternative forms of risk management (consultancy and certification) and the regression of other forms of hedging.

The trends of variable costs of the farms exhibit a clear preference for technical tools instead of financial tools in order to hedge risk. This creates also a stronger pressure on the environment (pesticides, fertilizers and water).

Policy measures should have the objective to invert these trends, improving or finding new tools more appropriate and convenient for farmers.

In order to be efficient, the allocation of public funds for economic risk management tools should not be horizontal, but rather strongly based on a territorial analysis of the demand, considering exposure (to what and where), vulnerability (major damages) and farm structure.

The livestock sector is affected by damages, but little answers are given to hedge risk for phytosanitary risk. Farms seem uninterested in the current financial tools.

Within the crop sector, the trend of costs of pesticides shows the lack of alternative and enough flexible management tools for phytosanitary risk.
Sanitary risks need a management designed at an upper scale, for instance through mutual funds.

Despite the exposure and the vulnerability of their territory, the trends of crop insurance costs are positive only for big farms in income and size. The other categories where the great part of Italian farms is inserted show a decrease in trend (Pontrandolfi, 2013).

Policy should re-think the scheme for insurance subsidies or introduce more adequate tools in order to encourage risk hedging in medium-small farms (for instance, investing more in advice systems or other financial tools).

The integration gives opportunities to use the potential synergies between risk management tools and other rural development measures of a more structural and management nature. First and foremost, these include agro-climatic-environmental measures, production diversification, irrigation infrastructures, technological and management innovations and formation-information-consultancy.

The effectiveness of this integration can be achieved only if the actions are applied at a collective level (groups of farms).

\section{Acknowledgement}

Authors thanks anonymous referee for helpful contribution to increase the value of the paper; however, authors are responsible for the comments and analysis carried out throughout the text.

\section{Funding Information}

The research project which led the analysis has been funded by Italian Agriculture and Forestry Ministry.

\section{Author's Contributions}

Authors shared all parts of the paper; by the way, Antonella Pontrandolfi and Felice Adnolfi carried out introduction section and methodology part. Fabian Capitanio and Barry Goodwin carried out data analysis section.

\section{Ethics}

The work carried out in this paper has not been published before on other Journals

\section{References}

Adinolfi, F., F. Capitanio, R. D'Auria, M. Guido and M. Di Domenico, 2012. Risk management in planning for rural development 2014-2020 an hypothesis for the activation of the Income Stabilization Tool measure in Italy. Università degli Studi di Napoli Federico II. 
Cafiero, C., F. Capitanio, A. Cioffi and A. Coppola, 2007. Risk and crisis management in the reformed European agricultural policy. Canadian J. Agric. Econom., 55: 419-441. DOI: $10.1111 /$ j.1744-7976.2007.00100.x

Capitanio, F. and F. Adinolfi, 2009. The relationship between agricultural insurance and environmental externalities from agricultural input use: A literature review and methodological approach. New Medit J., 3: 41-48.

Capitanio, F., M.D.C. Bielza, C. Cafiero and F. Adinolfi, 2011. Crop insurance and public intervention in the risk management in agriculture: Does farmers really benefit? Applied Econom., 43: 4149-4159.

Capitanio, F., F. Adinolfi and F.G. Santeramo, 2014. Environmental implications of crop insurance subsidies in Southern Italy. Int. J. Environ. Stud., 71: 179-190. DOI: 10.1080/00207233.2014.947737

Chatellier, V., 2011. Price volatility, market regulation and risk management: Challenges for the future of the CAP. Int. Agric. Policy, 1: 33-50.

De Castro, P., F. Adinolfi, F. Capitanio and S. Di Falco, 2011. Building a new framework for the common agricultural policy: A responsibility towards the overall community der aufbau einer neuen struktur für die gemeinsame agrarpolitik: Eine verantwortung gegenüber der gesamten gemeinschaft développer un nouveau cadre pour la politique agricole commune: Une responsabilité envers l'ensemble de la communauté. Eur. Choices, 10: 32-36. DOI: 10.1111/j.1746-692X.2010.00171.x

Di Falco, S., M. Bozzola, F. Adinolfi and F. Capitanio, 2014. Crop insurance as a strategy for adapting to climate change. J. Agric. Econom., 65: 485-504. DOI: $10.1111 / 1477-9552.12053$

Diaz-Caneja, M.B., C.G. Conte, C. Dittmann, F.J.G. Pinilla and J. Stroblmair, 2009. Agricultural insurance schemes. European Commission Joint Research Centre.
EC, 2005. Commission staff working document on risk and crisis management in agriculture. European Commission, Bruxelles.

Enjolras, G., F. Capitanio and F. Adinolfi, 2012. The demand for crop insurance combined approaches for France and Italy. Agric. Econom. Rev., 13: 5-15. DOI: $10.2139 /$ ssrn. 1836798

Enjolras, G., F. Capitanio, M. Aubert and F. Adinolfi, 2014. Direct payments, crop insurance and the volatility of farm income: Some evidence in France and in Italy. New Medit, 1: 31-40.

Goodwin, B.K. and A.K. Mishra, 2006. Are 'decoupled' payments really decoupled? An empirical investigation. Am. J. Agric. Econom., 88: 73-89.

Goodwin, B.K., M.L. Vandeveer and J.L. Deal, 2004. An empirical analysis of acreage distortions and participation in the federal crop insurance program. Am. J. Agric. Econom., 86: 1058-1077.

JEU, 2013. Regulation (EU) no $1305 / 2013$ of the European parliament and of the council of 17 December 2013 on support for rural development by the European Agricultural Fund for Rural Development (EAFRD) and repealing Council Regulation (EC) No 1698/2005. European commission, Journal of the European Union.

Mechle, R., J. Aerts, W. Botzen, F. Crick and A. Thieken et al., 2013. Green Paper on the insurance of natural and man-made disasters (COM(2013) 213 final). European Commission.

Pontrandolfi, A. and G. Nizza, 2011. Prospettive della gestione del rischio in agricoltura: Riflessioni per un sistema integrato per la pac post 2013. INEA Roma.

Pontrandolfi, A., 2013. Risk management tools in agriculture: Some reflections on the opportunities and limitations of the European Commission proposal. Politica Agricola Internazionale Int. Agric. Policy. 